\title{
Preliminary Study on Mixed Solvent Extraction of Zhaotong Lignite
}

$$
\text { Wen-fang WU }{ }^{1, a} \text {, Shuai } \mathrm{LI}^{1, \mathrm{~b} *} \text { and Kai-yi SHI }{ }^{1, \mathrm{c}}
$$

${ }^{1}$ Department of Chemistry and Chemical Engineering, Liupanshui normal university, Liupanshui, 553004, China

aemail: 664527244@qq.com, bemail: lishuailsls@163.com, cemail: 157263069@qq.com

Keywords: lignite, mixed solvent, extraction

Abstract. The extraction of Zhaotong lignite in Yunnan province was studied by using organic solvent 1- methyl-2- (NMP) and $\mathrm{CS}_{2}$ mixed solvent as extraction solvent. The effects of solvent ratio, rotation speed, coal particle size and extraction times on the extraction rate were investigated by multi - factorial experiments. The results showed that the extraction rate was the highest when the extraction times was 8 , and the extraction rate was $67.19 \%$. Finally, the infrared spectra of the extract were analyzed. The results showed that there were $\mathrm{C}=\mathrm{O}$ (around $1645 \mathrm{~cm}^{-1}$ ), $\mathrm{C}=\mathrm{C}$ (around 1506 $\mathrm{cm}^{-1}$ ) and $\mathrm{CN}\left(1303 \mathrm{~cm}^{-1}\right)$ ), CH2 / CH3 (around 2930, $\left.1429 \mathrm{~cm}^{-1}\right)$, and aryl ether (around $1264 \mathrm{~cm}^{-1}$ ).

\section{Introduction}

At present, China has proven lignite and sub-bituminous coal accounted for $55 \%$ of coal reserves, in which the reserves of volatile is equivalent to 100 billion tons of oil and gas resources[1,2]. In addition, lignite is also rich in montan wax and humic acid, which are available materials. Therefore, the extraction of lignite is one of the efficient and clean utilization ways [3,5].

\section{Elemental analysis and industrial analysis of raw coal}

The coal used in the experiment is Zhaotong lignite. The elemental analysis data of raw coal are listed in Table 1.

Table 1 Elemental analysis of coal samples

\begin{tabular}{lllll}
\hline coal samples & \multicolumn{4}{c}{ elemental analysis $/ \%$} \\
\hline \multirow{2}{*}{ Zhaotong } & Nad & Cad & Had & Sad \\
& 1.38 & 50.88 & 5.01 & 0.68 \\
\hline
\end{tabular}

\section{Results and discussion}

\section{Effect of solvent ratio on extraction rate}

Three samples of coal were placed in different beakers and the weight of each coal sample was $5 \mathrm{~g}$. The extraction solvent $\mathrm{CS}_{2}$ and NMP were injected into the beaker according to the proportion of 1: 1, 1: $1,2: 1$ by syringe[6,7]. The dosage of $\mathrm{CS}_{2}$ was $20 \mathrm{ml}, 30 \mathrm{ml}, 40 \mathrm{ml}$ respectively, and that of NMP was $40 \mathrm{ml}, 30 \mathrm{ml}, 20 \mathrm{ml}$. The solvent and coal samples were shaken, extracted $12 \mathrm{~h}$ into the centrifuge centrifuge, centrifuge 30min, centrifuge speed $8000 \mathrm{r} / \mathrm{min}$. After centrifugation, the supernatant was removed and the residual coal was washed with acetone, filtered and dried. Table 2 shows the effect of the solvent ratio on the extraction rate.

Table 2 Effect of solvent ratio on extraction rate

\begin{tabular}{cccc}
\hline solvent ratio & $1: 1$ & $2: 1$ & $1: 2$ \\
\hline extraction rate $1 \%$ & 30.14 & 20.52 & 23.63 \\
\hline
\end{tabular}

As can be seen from Table 2, when the ratio of CS2 and NMP was 1: 1 the highest extraction rate reached $30.14 \%$. This is because NMP itself can not form hydrogen bonds, but can form strong hydrogen bond with phenolic hydroxyl group in lignite. While $\mathrm{CS}_{2}$ can weaken the interaction of NMP, the interaction is reduced to the lowest in the proper solvent ratio, so that the non covalent bond force in coal is reduced, so as to improve the solubility of coal and increase the extraction rate. 


\section{Effect of rotational speed on extraction}

Take 4 samples of coal into the marked good cone flask, the weight of each coal sample was $5 \mathrm{~g}$, with solvent selected from the best ratio of 1: 1 . Then put the coal and extraction solvent on the oscillator shake, the oscillator speed was 50r / min, 100r / min, 150r / min, 200r / min. And then the experimental procedure was the same as above.

Table 3 Effect of rotational speed on extraction

\begin{tabular}{lllll}
\hline rotational speed $/ \mathrm{r} \cdot \mathrm{min}^{-1}$ & 50 & 100 & 150 & 200 \\
\hline extraction rate $/ \%$ & 34.51 & 37.20 & 41.29 & 43.33 \\
\hline
\end{tabular}

Table 3 shows that the faster the speed, the higher the extraction rate of lignite. When the rotation speed was $200 \mathrm{r} / \mathrm{min}$, the extraction rate was $43.33 \%$. This is because with the speed up, the impact of the extraction solvent on the lignite is greater, the more the solvent and coal particles contact. So the extraction solvent can better extract the organic solvent from the macromolecular network structure of coal.

\section{Effect of particle size on extraction rate}

Lignite is divided into +100 mesh, 100 200 mesh, 200 400 mesh, -400 mesh. 5g coal samples were weighed from each grade and then placed in a well-marked conical flask, with solvent selected from the best ratio of 1: 1. Place the conical flask in the shaker at $200 \mathrm{r} / \mathrm{min}$. And then the experimental procedure was the same as above.

Table 4 Effect of particle size on extraction rate

\begin{tabular}{ccccc}
\hline particle size/ mesh & +100 & $100 \sim 200$ & $200 \sim 400$ & -400 \\
\hline extraction rate $/ \%$ & 37.24 & 39.89 & 44.92 & 42.66 \\
\hline
\end{tabular}

Table 4 shows that the extraction of lignite firstly increased with the decrease of the particle size, and then the extraction rate decreased. The maximum extraction rate was $44.92 \%$ in $200 \sim 400$ mesh. When the particle size of coal is relatively small, the contact opportunity of the solvent molecules and the coal molecules is increased, and the extraction solvent can enter the coal molecule to extract the organic solvent. However, when the coal sample is too fine, it will change the distribution of associated minerals in the coal sample, which is not conducive to the extraction of coal, so the particle size of coal sample can not be too small.

\section{Effect of extraction times on extraction rate}

Weigh 4 parts 200 to 400 mesh coal samples, each coal sample weight $5 \mathrm{~g}$. Then put the coal and extraction solvent on the oscillator shake, the oscillator speed was $200 \mathrm{r} / \mathrm{min}$. And then the experimental procedure was the same as above.

Table 5 Effect of extraction times on extraction rate

\begin{tabular}{ccccc}
\hline Extraction times / times & 2 & 4 & 6 & 8 \\
\hline Extraction rate $/ \%$ & 55.74 & 61.85 & 65.62 & 67.19 \\
\hline
\end{tabular}

Table 5 shows that the extraction rate is higher and higher with the increase of the extraction times. When the extraction times were 8 times, the extraction rate reached the highest $67.19 \%$.The increase of the extraction times is equivalent to the increase of the extraction time and the increase of the solid-liquid ratio, which contributes to the improvement of the extraction rate.

\section{Analysis of extracts}

The extracts of Zhaotong lignite were analyzed by IR, and the IR spectra of the extracts were shown in Figure 1. 


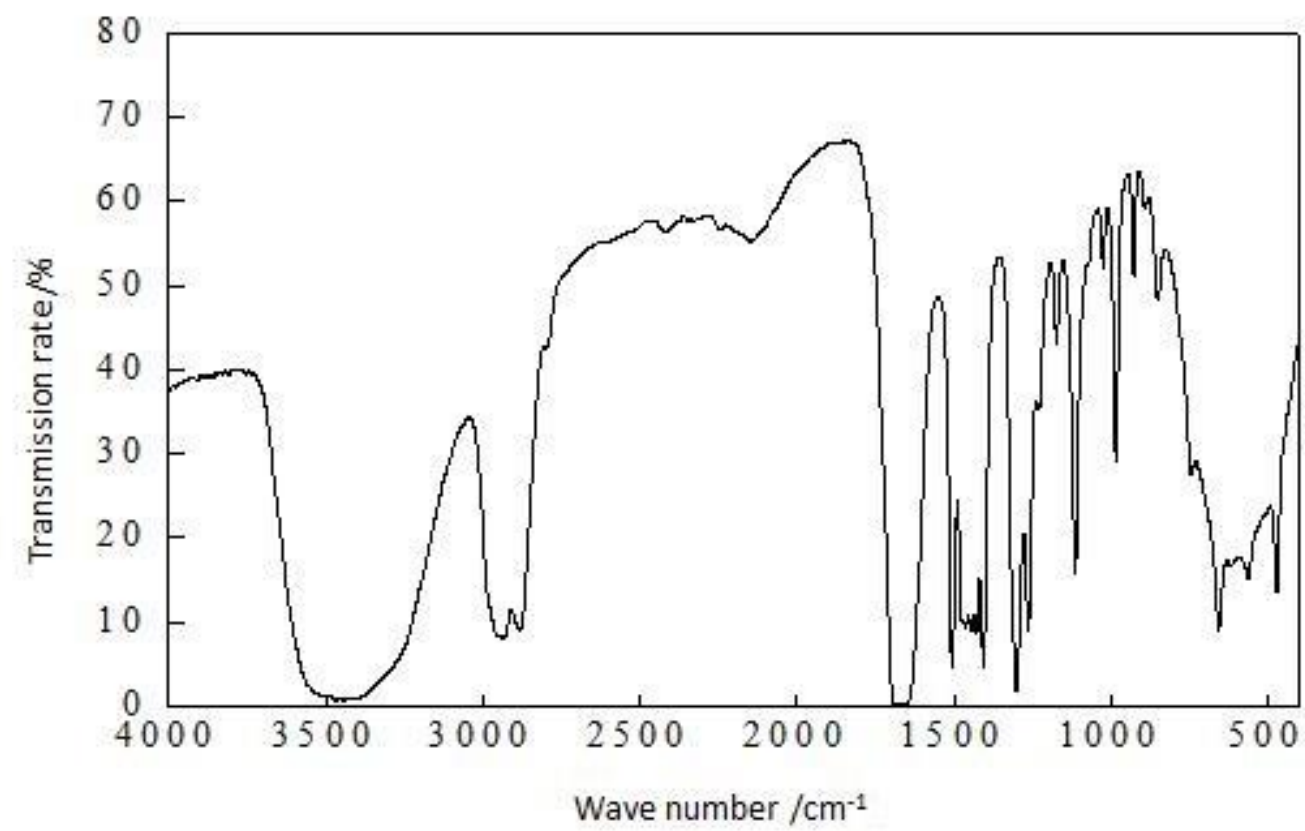

Fig. 1 Infrared Spectra of Zhaotong lignite extract

It can be known that $\mathrm{C}=\mathrm{O}\left(1668.42 \mathrm{~cm}^{-1}\right)$, aromatic hydrocarbon $\mathrm{C}=\mathrm{C}\left(1506.45 \mathrm{~cm}^{-1}\right), \mathrm{C}-\mathrm{N}(1303.2$ $\left.\mathrm{cm}^{-1}\right),\left(\mathrm{CH}_{2} / \mathrm{CH}_{3}\right)$ shear vibration $\left(1429.32 \mathrm{~cm}^{-1}\right)$, aryl ether $\mathrm{C}-\mathrm{O}\left(1264.4 \mathrm{~cm}^{-1}\right)$ and so on. The content of $-\mathrm{C}=\mathrm{O}$ was the most, followed by $\mathrm{C}-\mathrm{N}$, aromatic $\mathrm{C}=\mathrm{C}$ and carboxylic acid ion $-\mathrm{COO}-$, and the remaining functional groups were relatively few.

\section{Conclusion}

The highest extraction rate of mixed solvent conditions: solvent ratio of $1: 1$, speed of $200 \mathrm{r} / \mathrm{min}$, 200 to 400 mesh size fraction, extraction times 8 times, and the extraction rate reached $67.19 \%$.

Functional groups of extraction have $\mathrm{C}=\mathrm{O}$, aromatic hydrocarbon $\mathrm{C}=\mathrm{C},\left(\mathrm{CH}_{2} / \mathrm{CH}_{3}\right)$ shear vibration, aryl ether $\mathrm{C}-\mathrm{O}$ and so on. The content of $-\mathrm{C}=\mathrm{O}$ was the most, followed by $\mathrm{C}-\mathrm{N}$, aromatic $\mathrm{C}=\mathrm{C}$ and carboxylic acid ion -COO-, and the remaining functional groups were relatively few.

\section{Acknowledgement}

This research was financially supported by Guizhou "125 plan" key project of science and technology project(No.Qian jiao he zhong da zhuang xiang zi [2013] 026), National Natural Science Foundation of China (No. 50874107), Guizhou research laboratory platform of clean and efficient use of coal resources(NO. Qianke Platform [2011]4003), Guizhou province science and technology fund project(No. Qianke he J zi [2012]2306), Key Laboratory of Coal Processing and Efficient Utilization of Ministry of Education (No. CPEUKF1405), Liupanshui normal university creative team (LPSSYKJTD201401), Liupanshui normal university high level talent opening foundation (LPSSYKYJJ201402), Guizhou Key supported discipline (Qian Xue wei he zi ZDXK[2016]24),

Guizhou Institutions of Higher Education innovation team (Qian Jiao he rctdz [2015]69), Liupanshui Normal University Scientific Research Project (LPSSY201604) and Guizhou Provincial Department of education Youth Science and technology talent development project(Qian Jiao he KYzi [2016]270).

\section{References}

[1] Zhang Shuangquan, Wu Guoguang: Coal chemistry, edited by China University of Mining and Technology Press, Xuzhou(2009).

[2] LI Zhen, YU Wei, YANG Chao:Current status and prospect of low-rank coal upgrading and utilization (Mining Machinery, China 2013).

[3] AN Mao-yan, JIANG Rong-li:Status and analysis of low-rank coal flotation (Energy Technology and Management, China 2013). 
[4] QIN Zhi-Hong, WEI Xian-Yong, JIANG Chun: FTIR analysis of two fractions of bituminous coal $C S_{2}$ solvent fractionation (Journal of China University of Mining \& Technology, China 2005).

[5] QU Jin-zhou, TAO Xiu-xiang, TANG Long-fei:Characteristics of the surface properties of low-rank coal before and after flotation in Shenlong (China Coal, China 2014).

[6] JU Cai-xia, JIANG Fa-qin, WANG Fei-jun:GC / MS analysis of $C S_{2}$ extract from two kinds of bituminous coal by microwave-assisted extraction (Journal of Heilongjiang Institute of Science and Technology, China 2004).

[7] Liu Changming, Zong Zhimin, Wei Xianyong:Effects of Ultrasonic Water Treatment on Extraction Rate of $\mathrm{CS}_{2} / \mathrm{NMP}$ in Dongsheng Coal ( Journal of Xi'an University of Science and Technology, China 2008). 